\title{
Legal Principles and the Limits of Law
}

\section{Joseph Raz*}

Most people tend unreflectively to assume that laws belong to legal systems. "Most educated people," writes H. L. A. Hart, "have the idea that the laws in England form some sort of system, and that in France or the United States or Soviet Russia and, indeed, in almost every part of the world which is thought of as a separate 'country' there are legal systems which are broadly similar in structure in spite of important differences." 1 This includes for most people the assumption that laws differ from non-legal rules and principles. There are, for example, moral rules and principles, social customs, constitutions and regulations of voluntary associations, and so on, which are not laws. Many legal philosophers have tried to justify this common assumption. Various criteria have been offered for demarcating the limits of law, for testing whether or not a particular standard belongs to a particular legal system. Various suggestions have been made concerning the importance of the distinction between what is legal and what is not, and the ways in which, by preserving it, we promote our understanding of law and society. For it has often been acknowledged that the distinction is not an easy one to draw in precise terms, and that any reasonable test would admit the presence of borderline cases. Despite these difficulties many theorists have thought that the distinction is worth preserving, partly because it is not difficult to apply in the majority of cases and partly because it seemed to them crucial for a proper understanding of law and society.

On this, as on almost any other fundamental question, opinions differ. There have been theorists who disputed the possibility of drawing the distinction between laws and non-legal norms, or who thought that far from clarifying it actually obscures our understanding of law and society. Recently, in a powerful article, Professor Dworkin has joined those who challenge the orthodox position that what is law may be separated from what is not. But the way in which Professor Dworkin formulates his conclusion is revealing. "I conclude," he writes, "that ... we must reject the positivists' first tenet, that the law of a community is distinguished from other social standards by some test in the form of a master rule."2 He clearly believes that there is no test,

- Senior Research Fellow, Nuffield College, Oxford. M. Jur. 196t, Hebrew University, Jerusalem; D. Phil. 1967, Oxford.

1. H.L.A. HART, THE CONCEPT of LAw 2.3 (1961).

2. Dworkin, The Model of Rules, 35 U. CH. L. REv. 14, 45 (1967), reprinted under the title Is Law A System of Rules?, in Essiss in Legal Pullosomiy 25, 59 (R. Summers ed. 1968) [hereinafter cited as Dworkin, with page references to the original article and, in brackets, to the reprinted paper]. 
however complex, which distinguishes "the law of a community" from "other social standards," but he explicitly rejects only Hart's way of drawing the distinction by reference to "a master rule," the rule of recognition. As Professor Dworkin makes clear, he chooses to concentrate his attack on Hart, not just because he is concerned with the defects of Hart's theory, but because it is the most sophisticated version of the view he is challenging. In evaluating Professor Dworkin's case it is essential to try to separate those comments which bear mercly on Hart's views from those which go to the root of the matter and cast doubt on the advisability of drawing a distinction between laws and other standards or on the very possibility of doing so.

I am not concerned here with refuting Professor Dworkin's criticism of Hart or of "positivism," as defined by him, in general..$^{3}$ My main concern is to argue that there is nothing in Professor Dworkin's arguments to show that there is reason to abandon the attempt to draw the limits of law. I will also suggest some, though by no means all, of the reasons which should lead us to persevere in the attempt. Professor Dworkin's arguments turn on the crucial role that principles play in the law, and it is to the examination of legal principles that we must first turn. 4

3. If pressed to find allies I will certainly find them among those commonly known as legal positivists. $I$ doubt, however, whether on examination we will find any legal philosopher who fulfills Professor Dworkin's definition of a positivist. His positivist is as rare an animal as the mechanical jurisprudent. But that is a different story.

4. Throughout this essay the expressions "norm," "standard," "rulc," and "prin. ciple" are extensively used. The sense in which these terms are employed will cmerge in the discussion. The following diagram summarizes their relations to one another. Occal. sional deviant usages (see, e.g., pp. $827-28,835$ infra) will be distinguished.

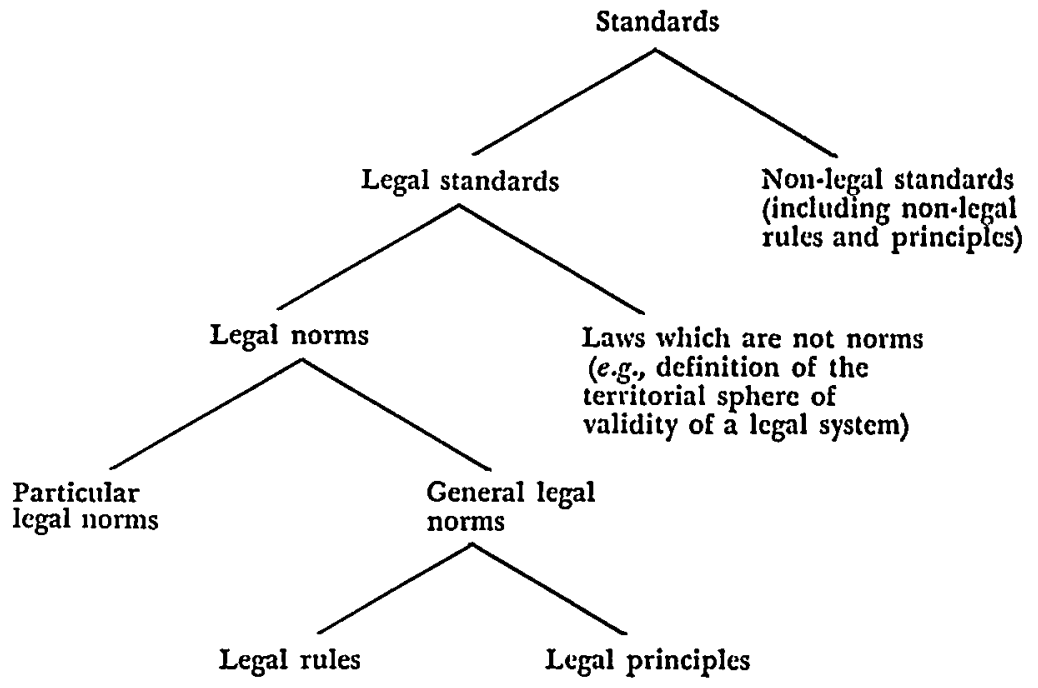




\section{Legal Rules and Legal Principles}

\section{A. The Individuation of Laws}

Classifying laws into logically distinct categories has always been one of the major tasks of legal philosophy. Many generations of theorists have shared in repeated attempts to analyze the logical characteristics of laws and to identify and contrast various types of laws in respect of their logical properties. Professor Dworkin's analysis of the nature of legal principles is yet another contribution to this venture. Professor Dworkin calls our attention to a logical distinction between various laws which has been neglected by some, and which he attempts to analyze: the distinction between rules and principles.

The classification of laws presupposes a solution to the more fundamental problem of the individuation of laws, i.e., an answer to the question "What is to count as one complete law?" A brief explanation must be given of both the nature of this problem, and of the reasons an answer to it is presupposed by any classification of laws.5

We find our law in statute books and law reports. These are neatly divided into separate judgments, statutes, regulations, by-laws, and so on. It might seem that to find what is one complete law is an easy task. Every section in a statute, every judgment of a court embodies one complete law. But to say this is to misunderstand the question. As Bentham reminded us in 1789:

What is a law? What the part of a law? The subject of these questions, it is to be observed, is the logical, the ideal, the intellectual whole, not the physical one: the law, and not the statute. An enquiry, directed to the latter sort of object, could neither admit of difficulty nor afford instruction. In this sense ... [s]o much as was embraced by one and the same act of authentication, so much as received the touch of the sceptre at one stroke, is one law: a whole law, and nothing more. A statute of George II made to substitute an or instead of an and in a former statute is a complete law; a statute containing an entire body of laws, perfect in all its parts, would not be more so. By the word law then, as often as it occurs in the succeeding pages is meant that ideal object, of which the part, the whole, or the multiple, or an assemblage of parts, wholes, or multiples mixed together, is exhibited by a statute; not the statute which exhibits them. ${ }^{6}$

5. For a more detailed discussion of these problems, see J. RAZ, Tiıe Cosceit of A LEGAL SYSTEM chs. 4, 6 (1970).

6. INTroduction to the Principles of Morhls and Legislation, in J. Bestilsi, I Fragment on Governarent with AN INTroduction to the l'rixchles of Monals asd LEGISLATION 429-30 n.1 (W. Harrison ed. 1960). 
In a sense Bentham's point is known to every student of law who, when in need to learn the law bearing on a problem, will turn first not to the law reports or statute books but to the legal textbook, whose purpose is to represent the content of the law in an orderly fashion while largely disregarding the fact that any given paragraph may be derived from various statutes and precedents. Authors of textbooks and students of law generally, however, while being largely indifferent $t^{7}$ to the original divisions of the law by the lawmaker, ${ }^{8}$ are equally indifferent to any other attempt to divide the legal material into separate and complete laws. Their interest is in the content of the law; its formal structure does not concern them. Not so the legal philosopher. He is sometimes more interested in the formal structure of laws than in their particular content. To study their formal structure, their logical properties, he must have a doctrine of individuation of laws.

Let me illustrate the point with a few examples. Let us assume that a legal philosopher tells us that all laws are commands. We produce three counter-examples. The first is a section in a constitution saying that "Parliament shall have power to enact laws concerning the rights and duties of property." The second is a section in a statute providing that "every person of age and sound mind shall have power to make a will determining the disposition of his property after death." The third is a statement made by a court in rendering judgment stating that "every person has a right to personal security." None of these, we claim, is a command; therefore, not every law is a command. Have we refuted the theory of our philosopher friend? We have done so only if the three statements we produced are each a statement of one complete law. For our friend may claim, as did Austin and Bentham, for example, that they are merely descriptions of parts of laws or deductions from proper descriptions of laws. He may claim that our constitutional provision does, indeed, establish a law which is a command. It is a command to all to obey any laws made by Parliament regulating the rights and duties of property. This was not the language used by the legislator, but this is the proper description of the constitutional law he made. Statements that Parliament has power to enact such laws made subsequent to the adoption of the constitution

7. Except occasionally for purposes of interpretation.

8. When there is a lawmaker. Much of the law is developed by way of custom and the constantly evolving practices of the courts. Some of the most important laws, as Professor Dworkin reminds us, were not formulated by legal institutions. They underlie institti. tional activities and are first formulated by commentators. 
are true statements of law, but they do not properly describe a law. They are valid deductions from a statement which does properly describe the law and which shows that it is really a command of a special type: a command to obey.

As to our second example, our philosopher friend may claim that, by enacting the section relating to wills which we have quoted, the legislator made not one complete law but a part of many distinct laws, all of which are commands. The laws relating to property, he would claim, are in fact enormously complicated commands prohibiting certain people from interfering with property in certain ways. These commands apply only to people not owning the property or not having certain other rights in it. The commands, therefore, include elaborate specifications of their conditions of application, and the statutory provision we cited is part of these conditions of application. It states in effect that a person should be exempt from the prohibition against interference if, e.g., a deceased owner of the property named him in his will as the future owner, and that other people will be exempt from the prohibition if he subsequently transfers the property or an appropriate right in it to them, etc. Thus, our friend will patiently continue, our mistake was to think that the statutory provision is a complete law, whereas in fact it is merely a part of many laws. Once we understand this, he will triumphantly conclude (expecting us to be able to deal on our own with our third example), we will see that all laws are indeed commands. For, as is by now clear, in his view the court's statement that every person has a right to personal security is not a statement of one law but a summary reference to many. The court in its reasoning alludes to the laws against murder, assault, and false imprisonment, among others, and to the laws commanding violators of these to pay damages.

It would probably be generally accepted that our philosopher friend is mistaken, that not all laws are commands. He is mistaken not because he is employing principles of individuation, but because he has accepted the wrong principles. Every theory about the logical types of laws presupposes a doctrine of the individuation of laws, and for the most part it can be attacked or defended only by attacking or defending its underlying doctrine of individuation. There is no need to tackle here the problem of the individuation of laws in general. ${ }^{0}$ It is, however, very important to be constantly aware of it when dis-

9. I have tried to do this elsewhere. J. RAz, supra note 5. 
cussing the status of principles. If we do this we will soon realize that not everything which looks like a legal principle is a legal principle, at least not in the sense that Professor Dworkin has in mind.

We often have need to refer summarily to a body of legal rules with. out specifying their content in detail. Such references are frequently made by courts in the course of justifying their decisions. These references usually take the form of a statement of a principle, but they are not statements of the content of laws of a special type, namely legal principles. They are merely a brief allusion to a number of rules. Someone may say that in his country the principle of freedom of specch is recognized by law. When asked what he means he may say that the only laws setting limits to the liberty to express opinions are concerned with libel and military security; that censorship of films, books and the theatre must be justified by the protection of infants; that there are detailed regulations guaranteeing access to the mass media to people representing all shades of opinions on public matters; and so on. His statement that in his country freedom of speech is recognized by law can thus be seen to be a summary reference to a great number of laws, not a statement of the content of a single law. Another person, by contrast, may say that a certain legal system incorporates the principle of freedom of speech because it contains a law instructing the courts and all public officials to protect freedom of speech in all cases, even those not governed by particular rules. This person's statement is a statement of the content of one particular law, and it is a principle in the sense in which Professor Dworkin employs the term. It imposes an obligation and thus guides the action of courts and officials.

Professor Dworkin is only dimly aware of the problem of individuation. He does say that not every statement of a rule is a complete description of it. ${ }^{10}$ Many such statements omit many of the exceptions which are part of the rule and which must be included in any complete statement of its content. He is, however, completely oblivious to the importance of the doctrine of individuation to a discussion of principles. In particular, he disregards the fact that some statements by courts which look like statements of legal principles are in fact no more than abbreviated references to a number of legal rules. It secms to me, to take just one of Professor Dworkin's examples of principles, that a court's statement that freedom of contract is not such an im.

10. Dworkin, supra note 2, at 25 [37]. 
mutable doctrine as to admit of no qualification ${ }^{11}$ is merely a reference to the fact that there are rules qualifying the freedom of contract and there is a rule granting the courts power to introduce further qualifications. (The exercise of this power is subject to principles guiding the discretion of the courts in general. But these principles are distinct from the power granted to the courts.)

The first lesson to be drawn from applying the doctrine of individuation to the discussion of legal principles is that the apparent multiplicity of principles is deceptive. Some apparent statements of principle are merely abbreviated references to a number of laws, not statements of the content of one complete legal principle.

\section{B. Conflicts Among Laws}

Bentham, Austin and many others assumed that valid laws do not conflict. They knew, of course, that conflicting statutory provisions and conflicting judicial opinions can easily be found, but they believed that in such cases what is valid are only the laws to the extent to which they do not conflict. In a complete representation of the law of a country all conflicts are resolved by the application of legal rules and principles such as that lex posterior derogat priori. The principles of individuation should be so framed to ensure that laws do not conflict. A single law may include many limitative and exceptive provisions, to use Bentham's terminology, qualifying the application of its main provision, and ensuring that it does not conflict with other laws. But one law may not conflict with, and thus qualify, another law.

This is not, however, the way we ordinarily think of the relation between non-legal rules and principles. We know not only that principles like "maximize total happiness" and "strive to increase equality" may conflict when applied to particular cases, but also that rules may sometimes conflict as well. Sometimes one can keep one's promise only by telling a lie. We do not normally think that such conflicts are merely apparent and that each rule in fact includes qualifications such as "keep your promise unless this entails telling a lie." We believe that sometimes we should lie rather than break a promise and sometimes we should break a promise rather than tell a lie, and although what we should do depends on general considerations there is no way of setting all of them down beforehand. We can attend to many problems only when they arise; we are unable to decide what

11. Id. at 24 [36]. 
to do solely on the basis of previously accepted rules. We are on the whole reconciled to the fact that rules may conflict and that they impose obligations which may be overridden in particular cases by contrary considerations. ${ }^{12}$

Professor Dworkin adopts an intermediate position on this issue. Legal rules, he claims, do not conflict whereas legal principles do. Indeed, he turns this into the first distinguishing characteristic between legal rules and principles:

The difference between legal principles and legal rules is a logical distinction. Both sets of standards point to particular decisions about legal obligation in particular circumstances, but they differ in the character of the direction they give. Rules are applicable in an all-or-nothing fashion. If the facts a rule stipulates are given, then either the rule is valid, in which case the answer it supplies must be accepted, or it is not, in which case it contributes nothing to the decision. ${ }^{13}$

This means, as Professor Dworkin explains, that if a legal rule stipulates that a certain act ought to be done in certain conditions, then, given that in a particular situation the conditions obtain, the act ought to be done. It cannot be argued that it ought not because of a second legal rule which qualifies the first, for on Professor Dworkin's account a legal rule includes all its exceptions and cannot conflict with another rule. "If two rules conflict, one of them cannot be a valid rule."1t This distinguishes legal rules from legal principles, since the latter may conflict.

This leads Professor Dworkin to the second distinguishing mark of legal principles, which is entailed by the first. Legal principles have certain relative "weights." Some have greater weight than others. This dimension of weight determines what ought to be done in cases to which conflicting principles apply. "When principles intersect ... one who must resolve the conflict has to take into account the relative weight of each."15 Since rules do not conflict they do not have this dimension of weight.

I would like to suggest that legal rules may conflict and have weights, and that therefore Professor Dworkin's remarks should not

12. Some philosophers dispute this view, but this is not the place to discuss the getleral problem in detail. For a convincing argument in favor of the view cxpresscd licre, see Singer, Moral Rules and Principles, in Essays in Moral Pulosolir' 160, $167(\Lambda$, Melden ed. 1958).

13. Dworkin, supra note 2, at 25 [37].

I4. Id. at 27 [40].

15. Id. at 27 [39]. 
be regarded as defining the characteristics of rules and principles. The issue here turns on which principles of individuation it would be best to adopt. It is possible to devise principles of individuation which guarantee that every rule includes all its qualifications and that no rules ever conflict with each other. But it would be wrong to accept such principles of individuation. The point at issue can best be illustrated by an example. The criminal law includes a rule prohibiting assault. This rule is qualified by various other laws. ${ }^{10}$ Assault is permitted in self-defense, in carrying out lawful orders, in cases of necessity. The rule is also qualified by general laws determining the territorial sphere of validity of the bulk of the laws of the legal system concerned. One might wish to claim, as did Bentham, for example, that no statement of the law against assault is a complete description of that law unless it enumerates all these qualifications. One may claim that the qualifying laws are not separate laws but only parts of the law prohibiting assault. To do so would be to accept a very misguided doctrine of the individuation of laws.

Consider the consequences of accepting this view of the individuation of laws. It will mean, of course, that not only the law against assault but also the laws against homicide, rape, and theft, and every other law, will include these and many other qualifying clauses. We will have fewer laws (the doctrine of self-defense, for example, will not be regarded as separate), but those which remain will be enormously complex. They will also be very repetitive, having much of their content in common (the doctrine of self-defense, for example, will be a part of each of the criminal laws).

To accept such a doctrine of individuation is to misunderstand the function of the principles of individuation. Because of the vast amount of legal material which constitutes one legal system, we need to divide it into smaller units called "laws" in order to be able to refer separately to parts of the total legal system. The principles of individuation are the method of carving small and manageable units out of the total legal material in a way which will promote our understanding of the law by classifying laws into various types and by showing how these laws interrelate and interact with one another. The principles of individuation which are necessary to avoid conflicts among laws yield enormously complex laws which are relatively independent; their inter-

16. The definitions of "assault" and some other offenses often include expressions such as "wrongful" and "unlawful." Such words serve to draw attention to the lact that these rules may conflict with other laws which qualify them. 
action with other laws is minimized; they are made to be as selfsufficient as possible. This relative independence is acquired at the cost of making each law very bulky; each is derived from a great number of statutes and cases; and they become repetitive. These were also, as we have seen above, the consequences of denying the status of a separate law to the laws conferring powers to legislate or make wills. For these reasons (among others) we must reject any doctrine of individuation which strives to avoid any conflict of rules by making them so much more complex and repetitive.

Instead we should adopt a doctrine of individuation which keeps laws to a manageable size, avoids repetition, minimizes the need to refer to a great variety of statutes and cases as the sources of a single law, and does not deviate unnecessarily from the (admittedly hazy) common sense notion of a law. Such a doctrine of individuation will result in a greater number of laws which interact with one another, modifying and qualifying each other. This approach is closer to the way lawyers ordinarily think about the law, and also illuminates im. portant connections among laws. It focuses attention on the fact that certain groups of laws are affected by certain other laws stipulating doctrines such as self-defense, necessity, etc., while others are not. In short, such a doctrine of individuation better explains the systematic interrelations between various parts of the legal system.

The result is that laws which are not principles may conflict. It is because they conflict or "interact" (to use Professor Dworkin's phrase) that they can modify and qualify one another. Consequently, Professor Dworkin is wrong in holding that principles can be distinguished from other laws because only they can conflict.

This still leaves Professor Dworkin's second point, relating to the "weight" of legal principles, untouched. Legal rules might arguably lack the dimension of weight even though they conflict. But perhaps talking of "weight" here is misleading. Since laws which are not principles conflict, the legal system includes some means of resolving such conflicts. But these means usually determine which one of any two conflicting laws prevails, and the same law always prevails when the two conflict. The law instituting self-defense or mistake of fact as an excuse always overrides the law prohibiting assault. With principles the situation is different. That one principle has more weight, is more important than another, does not entail that whenever they conflict (assuming that no other principle is involved) one ought to follow the more important principle. In determining what is to be done in 
every case, or type of case, the importance of the principles has to be considered in relation to the amount of good or harm done to the ends they seek to promote. In one case, or type of case, for example, one possible solution may greatly advance the goal of the less important principle, while doing only little harm to the goal of the more important principle. The alternative solutions may cause a great deal of damage to the goal of the less important principle while promoting only slightly the goal of the more important principle. In such cases the less important principle is to be preferred. In other cases the calculation may be different.

By somewhat modifying Professor Dworkin's second point, one might claim that though both rules and principles have relative weights, they behave differently in many instances of conflict. Conflicts between rules are determined solely by their relative importance; conflicts between principles are determined by assessing their relative importance together with the consequences for their goals of various courses of action. It seems to me that this is a correct observation of one important difference between rules and principles (in one sense of "principles") in most legal systems. It would be wrong, however, to regard this as a logical difference between rules and principles, or to take this feature to be a defining characteristic of principles.

First let us observe that there are some types of conflicts in which rules behave like principles. These are cases in which a rule conflicts with a principle. Such conflicts are, of course, possible on Professor Dworkin's account. He thinks that once they are brought before a court they may be resolved by amending the rule to avoid future conflicts. This sometimes happens, but at least before the court's decision and often, as I shall argue below, later, rules do conflict with principles. Such conflicts can be resolved either on the basis of the relative importance of the conflicting laws, disregarding the consequences for each law's goal of the possible solutions (and thus treating the principle as a legal rule is normally treated), or by taking into account both the relative importance of the laws and the consequences for the goals of each of the possible solutions (and treating the legal rule in the way legal principles alone are usually treated). In most cases (though not in all) the second method is followed; but, regardless of which method is used, it is apparent that in these conflicts rules and principles are treated in exactly the same way. ${ }^{17}$

17. Naturally, the assessment of the importance of a rule and of the consequences for its goal of various deviations from it depends largely on the reasons for the rule, which 
This observation does not deny that legal rules and principles sometimes behave differently in cases of conflict, and does not preclude one from making this difference the defining characteristic of principles. But it detracts from the attractiveness of such a definition. The reason for rejecting the suggested definition depends on the fact that rules and principles are not exclusively legal concepts. We distinguish between rules and principles in morals and other non-legal spheres. A definition of legal "rules" and "principles" which accounts for the non-legal use of these terms is preferable to any definition which does not fit their non-legal usage. It is quite clear that in many non-legal contexts rules and principles behave in conflict in precisely the same way-the way characteristic of the legal treatment of principles. This is not the place to argue this point at any length. Let us just remind ourselves of the conflict between the rules concerning lying and promising. When such conflicts occur we decide what we ought to do not merely by declaring that one rule is more important than the other and is always to be preferred, but by comparing the good and harm to the values protected by them in every case or type of case, sometimes preferring to follow one rule and break the other, sometimes preferring the opposite. I therefore suggest that the logical difference between rules and principles has nothing to do with the possibility of conflict or the way such conflicts are to be resolved. The different treatment of legal rules and principles in cases of conflict is not entailed by their logical differences but is a result of a legal policy. What that policy is we will be able to see after we establish the logical difference between these types of law.

\section{Rules and Principles Distinguished}

The distinction between rules and principles, as Professor Dworkin rightly observes, is a logical one. Legal rules and legal principles are laws of a different logical type. It would be wrong, however, to suppose that all the laws ordinarily called "rules" are of the same logical type, or that all the laws called "principles" are of the same type. ${ }^{18}$

are sometimes that it promotes the ends of certain legal principles. But in preciscly the same way the importance of legal principles and of deviations from them depends on the reasons for the principles-which are sometimes other legal principles. Compare, for example, the relation between the following two principles incntioncd by l'rofessor Dworkin: "[T]he courts will not permit themselves to be used as instruments of ine(uity and injustice." "[T] a "bargain' in which one party has unjustly taken advantage of the cconomic necessitics of the other." Id. at 24 [36].

18. Non-legal rules and principles are also of a variety of logical types, but this need not concern us here. 
Compare the rule prohibiting assault or the rule, mentioned by Professor Dworkin, that "[t]he maximum legal speed on the turnpike is sixty miles an hour," with the other rule he mentions, that "[a] will is invalid unless signed by three witnesses." 10 The first two rules erect prohibitions. They are legal norms guiding human behavior by pro. scribing a certain course of action. The third rule neither prohibits any action nor does it impose an obligation to behave in any way. It is not even a power-conferring rule (this being a type of rule distinct from duty-imposing rules), for it does not confer the power to make wills nor does it confer the power to witness wills. There are other rules conferring these powers on certain classes of persons. The rule itself qualifies the rule conferring power to make wills; it makes the successful exercise of this power depend on three witnesses having signed the will. ${ }^{20}$ Such rules, and there are many of them, are not norms, they do not guide behavior directly by providing reasons for action as duty-imposing or power-conferring rules do. Rather they affect one's reasons for action indirectly by qualifying the meaning or application of laws which are norms. ${ }^{21}$

Laws which are not norms are a most important category of laws. They have been neglected by most legal philosophers, who refuse to concede that not all laws guide behavior directly, that instead many guide it indirectly through their logical relations with other laws which are norms. Some of the laws which are not norms are often referred to as "principles." This is particularly true of those laws which govern a vast area of law: that is, those which are logically related to a great number of other laws, qualifying them and modifying their application. Thus the law determining the territorial sphere of validity of most of a country's law (which is clearly not itself a norm) is often referred to as a principle. It is not, however, a principle in the sense in which Professor Dworkin uses this term. (In cases of conflict, for example, it behaves like a rule.) Professor Dworkin is interested in principles which are norms; his principles are principles of obligation, they are standards which "point to particular decisions about legal obligations in particular circumstances."

19. Id. at 25 [37].

20. One may argue that it is not a separate law at all but merely part of the rule conferring power to make wills. I will assume that the principles of individuation, for reasons similar to those discussed above, permit one to regard this rule as a separate law. See pp. 831-32 supra.

2i. It should be noted that rules may conflict not only with rules of different logical type but also with rules of the same type. Compare the confliet between the rules concerning lying and promising.

22. Dworkin, supra note 2, at 25 [37]. 
The task of analyzing the various categories of legal and non-legal principles is a considerable one. I am only concerned to point out that not all legal principles are of the type discussed by Professor Dworkin. In the analysis I propose I shall follow him in concentrating attention exclusively on principles of obligation, and in trying to distinguish them, not from all other types of laws, but only from rules of obligation, the type they resemble most closely.

Rules and principles of obligation are similar; for, as Professor Dworkin rightly observes, it is "not always clear from the form of a standard whether it is a rule or a principle."23 Each states a reason that "argues in one direction." 24 That is to say, each states that a certain class of persons (the "norm-subject") ought to perform a certain act (the "norm-act") in certain circumstances (the "conditions of application"). ${ }^{25}$ The "ought" in both cases is a prima facie "ought," pointing to a reason for action, not an "ought all things considered." For both rules and principles may be overridden in certain circumstances by other rules and principles or by other reasons. Professor Dworkin creates the impression that the norm-subjects of all legal principles are the courts. ${ }^{26}$ But other people and institutions may also be the norm-subjects of principles (though it is true that legal principles, like all other laws, are enforced by the courts). One such example mentioned by Professor Dworkin himself is the American con* stitutional principle that Congress shall not abridge freedom of speech. Another example is the common law principle of the law of negligence, addressed to all the population and prescribing a duty of reasonable care. ${ }^{27}$

Principles are often stated in ways which leave their subjects unspecified. The statement of the principle, mentioned by Professor Dworkin, that an automobile "manufacturer is under a special obligation in connection with the construction, promotion and sale of his cars," makes clear that its subjects are automobile manufacturers. It is less clear whether another principle he mentions, that "no one may profit from his own wrong," 29 is addressed to the public at large or to the

23. Id. at 28 [40].

24. Id. at 26 [38].

25. This terminology is derived from G.H. von WRIGHT, NORM AND AGrion ch. $\mathfrak{j}$ (1963).

26. See, e.g., Dworkin, supra note 2, at 29-31 [41-44].

27. I shall argue below that Professor Dworkin is wrong in denying (id. at 28.29

[40-41]) that this is a principle. See pp. 841-42.

28. Dworkin, supra note 2, at 26-27 [39].

29. Id. at 25-26 [37-38]. 
courts. A more detailed statement of the principle is needed to determine that. That ordinary statements of principles do not set out in detail all their content should surprise no one, and should not lead to the conclusion that the omitted parts do not exist. In the statement of principles their relative weight is seldom mentioned. Similarly, the conditions of application of principles are sometimes omitted. Some principles are universal in the sense that the norm-act ought to be done whenever there is an opportunity to do so, while others are to be applied only in certain circumstances.

The conditions of application of a principle are not automatically narrowed by the fact that it conflicts with an established rule. The principle that no one may benefit from his wrong always applied to murderers inheriting by the will of the murdered person, despite the fact that their right to inherit was protected until 1889 by a rule. It is because it always applied to such cases that the court in Riggs $v$. Palmer $^{30}$ could, as Professor Dworkin reminds us, ${ }^{31}$ make an exception to the rule in the case of a murderer. Since principles apply to cases which are regulated by contrary rules, one cannot observe that words like "reasonable" and "unjust" make "the application of the rule which contains [them] depend to some extent upon principles ... and in this way makes that rule itself more like a principle" and then argue that it is nevertheless only a rule because each of "these terms restricts the kind of other principles on which the rule depends." 32 In general, all rules are subject to all principles and may" be overridden by any of them in particular circumstances. This is indeed one of the main points which Professor Dworkin is rightly anxious to establish. If a law establishing standards of reasonableness is a rule, then it is liable to be overridden by principles like any other. It is hardly plausible to suggest that the function of words like "reasonable" is to immunize the law against general considerations embodied in certain principles. Their function is to do precisely the opposite. It is true that laws prohibiting unreasonable restraints of trade or damage done by negligence do not in themselves embody or refer to all the considerations embodied in all the principles of law; but no principle does either. They are principles of exactly the same nature as the principle, mentioned by Professor Dworkin, that "the courts must examine purchase agreements [of automobiles] closely to

30. 115 N.Y. 506, 22 N.E. 188 (1889).

31. Dworkin, supra note 2, at 29 [41-42].

32. Id. at 28.29 [41]. 
see if consumer and public interests are treated fairly," or the other principle he quotes, that the courts generally refuse to enforce a bargain in which "one party has unjustly taken advantage" of another. They are principles, and like every principle embody one consideration or set of considerations which, though of very great weight in their own sphere, are to compete in particular cases with other more general principles.

The distinction between rules and principles of obligation both in law and outside it turns on the character of the norm-act prescribed. Rules prescribe relatively specific acts; principles prescribe highly unspecific actions. Generic acts, types of acts, are of various degrees of specificity. An act is highly unspecific if it can be performed on different occasions by the performance of a great many heterogeneous generic acts on each occasion. It is more specific to the extent to which there is only a small number of generic acts by the performance of which it is performed. Smoking is a highly specific act which is performed by smoking a pipe, a cigarette or a cigar, but not by many other generic acts. Assault, murder, rape, and speeding are likewise relatively specific acts. Promoting human happiness, respecting human dignity, increasing productivity, and behaving negligently or unjustly or unreasonably are highly unspecific acts. It is because of this that we say rules prescribe or proscribe the first class of acts, whereas principles prescribe the second (to the extent that these types of behavior are governed by norms at all). The distinction between rules and principles is, on this analysis, one of degree, since there is no hard and fast line between acts which are specific and those which are un. specific. Consequently, there will be many borderline cases where it will be impossible to say that we definitely have a rule or definitely a principle.

The suggestion that it is this logical distinction between the type of norm-acts prescribed which underlies much of our ordinary usage of the terms "rules" and "principles" may be greeted with some suspicion. We feel that rules and principles play different roles in practical reasoning whether in the law or outside it and that the suggested distinction does not seem to explain this. In fact, however, the logical distinction does explain some of these differences and it indicates how to explain the rest.

Since highly unspecific acts can be performed by performing on

33. Id. at 24 [36]. 
different occasions a variety of more specific acts, the opportunities for performing them encompass the opportunities for performing the more specific acts and are more general than the latter. Norms prescribing highly unspecific acts, consequently, must be justified by more general considerations bearing on a wider area of human activity. Since we justify considerations which apply to a limited range of situations and actions by more general considerations, principles can be used to justify rules but not vice versa. This is, perhaps, the most important difference in the role of rules and principles in practical reasoning in general, and it can be explained by means of the distinction I have suggested. This does not explain all the differences between rules and principles in the law. These, though dependent on the logical distinction, do not derive from it alone. They depend also on various constraints imposed by general legal policies and goals.

\section{The Role of Principles in the Law}

Let me start with a brief survey of five different purposes for which principles are used in the law. I will then make a general comment on their relation to other laws. The extent to which principles are used for these different purposes varies greatly among different legal systems. Even within one legal system some principles are used for all of them, while others are restricted to a few; and in some branches of the law principles are relied on more extensively than in others. I will not try to analyze in detail the role of principles in any particular legal system. My aim is only to isolate some of the different tasks principles may be assigned. These tasks are of a very general nature. Further subdivisions are needed for a complete account of the functions of principles. I will introduce one subdivision in a later section, but otherwise I shall restrict myself to the more general categories. Though the tasks identified can be performed by various types of principles, I shall as before confine the discussion to principles of obligation.

1. Principles as grounds for interpreting laws. This is perhaps the most extensive and least inhibited use to which virtually all principles are put. Principles are used for the interpretation of all laws, including other principles of a more restricted application. There is a very strong presumption in most legal systems that other things being equal an interpretation which makes a law conform to a principle is to be preferred to one which does not. Obviously, some interpretations 
often conform better to some principles than others, and the courts have to decide which interpretation to prefer. This role of principles is of the utmost importance since it is a crucial device for ensuring coherence of purpose among various laws bearing on the same subject. The importance of this function of principles can be gathered by comparing various legal systems which, despite great similarity in their rules, reach different conclusions in many cases because they apply different principles for their interpretation.

2. Principles as grounds for changing laws. The first function of principles merges into the second, since the borderline between an interpretation of a law and its amendment is notoriously a blurred one. Nevertheless the two functions are distinct, and it is not difficult to distinguish between them in the majority of cases. The doctrine of precedent, where accepted, commonly includes the understanding that laws developed through precedent are subject to amendment by the use of principles. This does not mean that judge-made rules are often upset; for, as Professor Dworkin reminds us, principles are often conservative in nature. Subordinate legislation is also subjected to relatively extensive review in light of legal principles. Though subordinate legislation, unlike judge-made law, is often amended on the ground of being in conflict with principles, it is seldom annulled for that reason. Many legal systems, however, stipulate that subordinate legislation must stand some test of reasonableness, thus rendering it void or voidable if it contradicts very fundamental principles. Principles are used much more sparingly when parliamentary legislation is concerned, except in countries which have a formal constitution from which certain principles can be shown to derive.

3. Principles as grounds for particular exceptions to laws. Sometimes a law is not applied to a case on which it bears on the ground that to do so in those particular circumstances would sacrifice important principles; but the law is not thereby modified. This may often occur in countries where the doctrine of precedent is not recognized but where principles are allowed to override rules in particular circum. stances. In common law countries this use of principles is more restricted, but nonetheless of considerable importance. The principle of laches, for example, is one of a group of principles of equity which is characteristically used in this way. In contrast we may remember that the principle "no one may profit from his own wrong" is characteristically used in the second manner described earlier, i.e., as ground for changing and qualifying rules. 
4. Principles as grounds for making new rules. When principles but no other laws apply to a certain range of problems, courts act to regulate the area by making new rules. This is a very important way in which the common law develops: new rules are made on the basis of established principles.

5. Principles as the sole ground for action in particular cases. There are situations in which what ought legally to be done is determined directly by the application of various principles to the case. This function of principles is radically different from those previously mentioned, for here principles do not operate through the mediation of rules. They are not grounds for the interpretation or modification of rules, nor do they compete with them or serve as grounds for creating them. It is easy to underestimate the extent to which principles are used in this way in most countries. The whole area of sentencing is governed almost exclusively by principles. The activities of public officials and administrative agencies are largely governed by principles in this fashion. The law confers certain powers on the agency and directs it to use them to promote certain policy goals in accordance with general principles. The exercise of discretionary powers is typically guided by principles rather than rules.

It is true, nevertheless, that on the whole there is a marked tendency in the law of many countries not to rely on the direct application of principles but to use them to govern the operation of rules in the ways indicated above. This is particularly true when individuals rather than courts and officials are the norm-subjects of the principles.

Some of the reasons for preferring rules to principles in the direct regulation of behavior have to do with the particular conditions of various countries or of different branches of the law. But at "least one general reason for this preference is fairly obvious. Principles, because they prescribe highly unspecific acts, tend to be more vague and less certain than rules. On the other hand, and for the same reason, they are particularly suitable for incorporating into the law very general goals and values, whereas rules are more apt to reflect more concrete considerations which apply to particular situations.

Since the law should strive to balance certainty and reliability against flexibility, it is on the whole wise legal policy to use rules as much as possible for regulating human behavior because they are more certain than principles and lend themselves more easily to uniform and predictable application. It is on the whole advisable to limit the use of principles to govern the creation and application of rulcs 
in order to ensure adequate flexibility in changing them and to prevent some of their unforeseen and undesirable effects. Some areas, such as governmental activities, cannot be adequately regulated by rules, and they must be directly governed by principles. But these cases are exceptional. Since in the use of rules the premium should be on certainty, whereas in the use of principles the premium is on flexibility, it is wise to accept relatively simple methods of resolving conflicts between rules which will not detract from the predictability of their application. No similar reasons apply to the methods of resolving conflicts between principles. This explains the difference noted above between the treatment of rules and principles in cases of conflict. The difference stems from reasons of legal policy. It is not a logical difference between the concepts of a rule and a principle.

In fact, all the comments made in this section concerning the relative roles of rules and principles apply only to their use in the law and similar institutions and are not entailed by the concepts of a rule and a principle. In morality, where certainty and uniformity are gen. erally less valued than correctness of judgment, rules have a much more limited role to play than in the law. Principles are to be regarded as governing directly most occasions for action and judgment affected by moral considerations. For the same reason conflicts of rules and conflicts of principles are not, in moral assessments, treated differently.

\section{Principles and the Limits of Law}

By the thesis of the "limits of law" I mean the position that there is a test which distinguishes what is law from what is not. Professor Dworkin's writings in effect contain three arguments, each of which is partly dependent on his theory of principles, against the thesis of the limits of law. ${ }^{34}$ While only two of these arguments are explicitly directed against this thesis, all of them, if valid, undermine it. In the remainder of this article I shall show that each of Professor Dworkin's arguments must fail and that there is good reason to persevere in the

34. "The Model of Rules" is perhaps not altogether clear that all forms of the thesis of the limits of law are to be rejected, though it plainly opposes one version of the thesis by rejecting the tenet "that the law of a community is distinguished from other social standards by some test in the form of a master rule." Id. at 45 [59]. Professor Dworkin has, however, confirmed to me in conversation that these arguments are directed against the thesis of the limits of the law generally and has taken such a position in his lectures at Oxford University in 1971. 
attempt to construct a test for distinguishing what is law from what is not. I hope in the course of this discussion to throw some light on how such seemingly disparate matters as the thesis of the limits of law, the nature of rules and principles, the role of judicial discretion, and the criterion of the identity of a legal system are related.

\section{A. Judicial Discretion}

Professor Dworkin's first argument is a result of his theory of judicial discretion. ${ }^{35} \mathrm{He}$ distinguishes three senses of discretion. In the two weak senses "discretion" means "judgment" and "finality." "Sometimes," explains Professor Dworkin,

we use "discretion" in a weak sense, simply to say that for some reason the standards an official must apply cannot be applied mechanically but demand the use of judgment. ... .

Sometimes we use the term in a different weak sense, to say only that some official has final authority to make a decision and cannot be reviewed and reversed by any other official. ...

I call both of these senses weak to distinguish them from a stronger sense. We use "discretion" sometimes . . . to say that on some issue [an official] is simply not bound by standards set by the authority in question. ${ }^{36}$

The thesis that judges have discretion in the strong sense ${ }^{37}$ means that there are cases which they are legally entitled to decide and in which no one correct decision is determined by standards of law. The thesis of judicial discretion does not entail that in cases where discretion may be exercised anything goes. Such cases are governed by laws which rule out certain decisions. The only claim is that the laws do not determine any decision as the correct one.

Professor Dworkin argues that (1) the law includes some principles as well as rules. From this he concludes that (2) the courts never have discretion in the strong sense. It follows, though he does not draw the conclusion at this point, that (3) the thesis of the limits of law is wrong. I shall argue that (3) does indeed follow from (2), but that (2) does not follow from (1) and is in any case wrong.

35. See Dworkin, Judicial Discretion, 60 J. Pulc. 624 (1963). Professor Dworkin has reformulated his theory in "The Model of Rules" (see Dworkin, supra note 2, at 32-40 [44-54]) to meet some of the objections raised by G.C. MacCallum, Jr., in his reply to Dworkin's first paper. See MacCallum, Dworkin on Judicial Discretion, 60 J. I'lll. 638 (1963).

36. Dworkin, supra note 2, at 32-33 [45-46].

37. I shall henceforth be concerned only with "discretion" in this sense, and only" this sense is involved in what I shall call the "thesis of judicial discretion." 
If courts are never entitled to exercise discretion (in the strong sense) it follows that all the reasons, rules and principles which they are entitled to rely on are part of the law. There is one important exception to this conclusion; those standards which are applied because they are the standards of some other legal system or organization, the standards of which the law respects and enforces, are not part of the law. The exception covers those laws of other states which are recognized and enforced according to the rules of private international law. It also extends to contracts and the rules of voluntary associations recognized by law, and to social, moral and religious standards of individuals and communities which are taken into account for some legal purposes (such as mitigation of punishment or exemption from military service) or as creating presumptions of fact as to the behavior or intention of litigants. When referring to such standards in their judgments the courts quite clearly do so not because they are part of the law but because the law makes it its business to recognize and give support, to a certain extent, to standards of other organizations, communities or individuals. ${ }^{38}$

This exception apart (and, however important, it does not affect Professor Dworkin's case against the thesis of the limits of larw), it follows from Professor Dworkin's views on judicial discretion that all the reasons which the courts are entitled to use in justifying decisions are part of the law. All the reasons for a decision are legal reasons, for the law uniquely determines which decision is the correct one. ${ }^{39}$ Now it seems to me true that on various occasions the courts are entitled to rely on every reason which is endorsed by part of the community for some purpose or other. It follows, therefore, from Professor Dworkin's view on judicial discretion that the thesis of the limits of law is wrong at least to the extent to which it claims that it is possible to distinguish between the law and non-legal social standards.

If, on the other hand, courts do have discretion, then in cases in which they are entitled to exercise discretion they act on standards which are not part of the law. Therefore, though every social standard may figure in a court's decision, it does not follow that all of them are laws. The opportunity is given to those who support the thesis

38. On this problem see Raz, The Identity of Legal Systems, 59 CALuF. L. Rev. 795
(1971.) The courts may occasionally rely on the wrong reasons. I am concerned here only
39. The with the reasons which they are entitled to usc. 
of the limits of law to draw a distinction between the standards used by courts which are law and those which are not. How is one to decide whether courts do or do not have discretion?

Professor Dworkin is primarily concerned to argue that there are legally binding principles. But this has never been denied by anyone, least of all by the positivists. Indeed, Austin could not have denied that some principles are legally binding while remaining true to his theory of law. The most fundamental tenet of his theory is that the commands of a sovereign are law, and there is nothing to prevent a sovereign from commanding that a principle shall be binding. Professor Dworkin's mistake lies in assuming that when Austin was talking about commands he was referring to what Professor Dworkin calls rules. But this is not the case. Neither does Hart use "rules" in the same sense as Professor Dworkin. By "rules" he means what Professor Dworkin seems to mean by "standards," namely rules, principles or any other type of norm (whether legal or social)..$^{40}$

The crux of the argument lies in the inference that since some principles are law judicial discretion does not exist. Professor Dworkin says very little on this. The reason, I suspect, is that he rightly sees that other theorists, not only the positivists, exaggerated the scope of judicial discretion because they failed to attend to the role principles play in the law. They tended to assume that whenever a rule is vague the court has discretion and did not see that sometimes the rule when read in light of some principles is not vague and does not leave room for discretion. "A set of principles," as Professor Dworkin reminds us, "can dictate a result." 11 But that it sometimes can does not mean that it always does. And it is this that Professor Dworkin has to establish to make his case against judicial discretion. Unfortunately, he does not even try to establish this point.

I suppose that there might be a legal system which contains a rule that whenever the courts are faced with a case for which the law does not provide a uniquely correct solution they ought to refuse to render judgment. In such a system there would be no judicial discretion. But, whether or not such a system can exist, few if any legal systems in fact contain such a rule. In most legal systems there are at least

40. Of course both Austin and Hart would maintain that some principles are not part of the law. But this is no more than to say that they believe in the thesis of the limits of law. It should be noted that I am using "standards" to corcr not only norms but also generally accepted reasons for action.

41. Dworkin, supra note 2, at 36 [49] (cmphasis in original). 
three different sources of judicial discretion. Let me survey them briefly.

1. Vagueness. Vagueness is inherent in language. It is a problem courts have to face very frequently. As noted above, principles as well as rules of interpretation can sometimes solve problems of vagueness without leaving room for discretion. But principles themselves are vague, and discretion in cases of vagueness cannot be dispensed with so long as courts are entitled to render judgment in such cases.

2. Weight. Though principles sometimes limit the scope of the courts' discretion, they tend on the whole to expand it. For rensons noted earlier, ${ }^{42}$ the law usually determines with precision the relative weight of rules. Not so with principles. The law characteristically includes only incomplete indications as to their relative weight and leaves much to judicial discretion to be exercised in particular cases. The scope of discretion is in fact doubly extended, since not only must the relative importance of principles be determined, but also the importance relative to each principle of deviating from it or of following it on particular occasions. This matter is usually entrusted to judicial discretion.

That courts have discretion as to weight does not, of course, mean that the law has nothing to contribute to the solution of the case. It contributes some of the elements for a solution, but not all the elements necessary to dictate a uniquely correct solution. In such cases the law dictates what considerations have to be taken into account, but not what weight to assign to each of them or to actions in accordance with or contrary to each of them in particular cases.

3. Laws of discretion. Most legal systems contain laws granting courts discretion, not only as to the weight of legally binding considerations, but also to act on considerations which are not legally binding. Such discretion may be, and usually is, guided by principles. These principles, however, do not dictate the considerations to bc taken into account, but merely limit the range of the considerations.

One may distinguish between substantive principles, which dictate a goal to be pursued or a value to be protected, and principles of discretion, which guide discretion by stipulating what type of goals and values the judge may take into account in exercising his discretion. Compare the following two sets of hypothetical principles. (a) "Car manufacturers have a duty to protect the public from accidents." "In-

42. See pp. 832-42 supra. 
creased productivity and efficiency should be the prime objective of public corporations." "The validity of standard contracts is contingent on their not taking advantage of the economic necessities of the weaker party." "The law favors security of title." (b) "The courts will not enforce unjust contracts." "Public corporations should act for the general good." "Whatever is contra bonos mores et decorum the principles of our law prohibit." The first group of principles set particular considerations to be acted on. They may be vague and they do not specify the weight to be given to each consideration, but the consideration prescribed is clear enough and is not a matter left to the courts' discretion. Principles of the second group, on the other hand, do not stipulate what considerations should be acted on. They merely specify the type of considerations which may be taken into account and leave the rest to the officials or the courts addressed by the principles. Rather than negating discretion, they presuppose its existence and guide it. What is "unjust" or "for the general good" is a matter of opinion and the courts or officials concerned are instructed by law to act on their own views. The law does not impose its own views of justice or the common good. Rather, it leaves the matter to the discretion of the courts or the officials. Many of the principles governing the action of the courts and the executive are principles of discretion..$^{43}$ Such principles, far from proving the absence of judicial discretion, are a manifestation of a legal policy to rely on and make use of judicial and administrative discretion in order to increase the flexibility of the law and improve the procedures for its constant review to meet changes in circumstance and opinion.

We must conclude that legal principles do not exclude judicial discretion; they presuppose its existence and direct and guide it. The argument from the absence of judicial discretion against the thesis of the limits of law must therefore be rejected. It should be noted, however, that judicial discretion is not arbitrary judgment. Courts are never allowed to act arbitrarily. Even when discretion is not limited or guided in any specific direction the courts are still legally bound to act as they think is best according to their beliefs and values. If they do not, if they give arbitrary judgment by tossing a coin, for example, they violate a legal duty. A judge must always invoke some general reasons. He has no discretion when the reasons are dictated by law. He has discretion when the law requires him to act on reasons

43. Many of the principles mentioned by Professor Dworkin are of this kind. 
which he thinks are correct, instead of imposing its own standards. When discretion is denied the law dictates which standards should be applied by all the judges. When discretion is allowed each judge is entitled to follow different reasons but he must believe that they are the best. Otherwise, discretion can be equated only with arbitrariness, whim, and caprice.

\section{B. "Sources" of Legal Principles}

Legal principles, like other laws, can be enacted or repealed by legislatures and administrative authorities. They can also become legally binding through establishment by the courts. Many legal sys. tems recognize that both rules and principles can be made into law or lose their status as law through precedent. Rules and principles differ in this respect. A court can establish a new rule in a single judgment which becomes a precedent. Principles are not made into law by a single judgment; they evolve rather like a custom and are binding only if they have considerable authoritative support in a line of judgments. Like customary law, judicially adopted principles need not be formulated very precisely in the judgments which count as authority for their existence. All that has to be shown is that they underlie a series of courts' decisions, that they were in fact a reason operating in a series of cases.

This is recognized by Professor Dworkin. He does, however, add a third "source" of legally binding principles: "judgments of the community at large or some identifiable segment thereof." 44 And he adds in a footnote: "On some occasions, in some kinds of cases, moral principles accepted as standards within the community will figurc as good reasons for a legal decision, just as, on other occasions, in other kinds of cases, will standards otherwise established. In this sense, such principles are part of the legal system, if it is helpful to talk about law as a system at all, and the flat statement that law and morals are separate systems is misleading." 45 The morality that Professor Dworkin has in mind consists of those moral views which became social norms in the community. No supporter of the thesis of the limits of law has ever denied that some social norms can be legal norms as well. The legislator can make a social norm into law either by direct enactment or by stipulating that social customs of a certain type should

44. Dworkin, supra note 35, at 635 (1963).

45. Id. at 635 n.9. 
be binding as law. By the doctrine of precedent the courts can do the same. To admit as much does not weaken in the least the thesis of the limits of law.

To challenge the thesis it has to be established that all social norms are automatically (without prior legislative or judicial recognition) binding as law at least to the extent to which they do not conflict with laws created by legislation and precedent. If this were the case in all legal systems the thesis of the limits of law would indeed be badly shaken and would need a far-reaching reformulation. In his subsequent remarks Professor Dworkin implies that this is in fact the case. ${ }^{46} \mathrm{I}$ think that he is mistaken, and it is worth pausing to examine the source of his mistake.

In most countries one of the most general principles restraining judicial discretion enjoins judges to act only on those values and opinions which have the support of some important segment of the population. ${ }^{47}$ There are various grounds on which the principle can be justified, none of which in itself justifies its full scope. It can be justified on democratic grounds; it can be defended by arguing that a judge whose actions affect the fortune of many should not trust his own judgment if it is not supported by learned opinion; it can be argued that laws out of tune with community values are unlikely to achieve their aim or will have some undesirable consequences. Ench of these justifications, and others that can be used, interprets the principle somewhat differently. A close study of the matter will no doubt distinguish between various related principles which sometimes reinforce each other and sometimes conflict, or which apply to different situations. All these principles restrain but do not exclude judicial discretion. They do not oblige the courts to enforce any specific social norms. They limit their freedom to act on what they think is right by making it conditional on their ability to show that they are not alone in that opinion. There is, therefore, no reason to regard these principles as converting all social morality into law or as undermining the thesis of the limits of law.

They have, however, a curious, though perhaps not surprising, effect on judicial rhetoric in some countries and especially in the United States. As they should, courts tend to justify judgments based on discretion by arguments designed to show that the decision is a good

46. Id. at 635 et seg.

47. The main device controlling courts' values and idcology is, of course, not this principle, but the methods of appointing or electing judges. 
one, ${ }^{48}$ and by other arguments to show that the decision conforms to the views of some segment of the population. Unfortunately, some judges like to claim that the values they endorse are not merely the values of some but embody the national consciousness, represent the national consensus, are universally acknowledged, etc. This is perhaps harmless rhetoric if it is understood as such. Professor Dworkin, however, urges us to give literal interpretation to such pronouncements from the bench. The courts apply what they think are community values. It follows that it is wrong to regard them as acting on their own beliefs as legislators do. They may be wrong in their views of what the values of the community are, but if so they are wrong on a point of law, for since they are bound to apply community values these are part of the law.

This literal interpretation of judicial rhetoric is made possible only if one is prepared to join the courts in endorsing two really harmful myths. One is the myth that there is a considerable body of specific moral values shared by the population of a large and modern country. The myth of the common morality has made much of the oppression of minorities possible. It also allows judges to support a partisan point of view while masquerading as the servant of a general consensus. The second myth is that the most general values provide sufficient ground for practical conclusions. This myth holds that, since we all have a general desire for prosperity, progress, culture, justice, and so on, we all want precisely the same things and support exactly the same ideals; and that all the differences between us result from disagreements of fact about the most efficient policies to secure the common goals. In fact, much disagreement about more specific goals and about less general values is genuine moral disagreement, which cannot be resolved by appeal to the most general value-formulations which we all endorse, for these bear different interpretations for different people.

The courts tend all too often to claim that a specific policy is entailed by belief in some general value, thus avoiding a concrete justification of their decision, maintaining the rhetoric of common goals and community values and endorsing partisan positions without admitting it. Some judges may themselves be captives of the myths they help to perpetuate. But the fact that they are misled should not mis-

48. Though judges are entitled, sometimes, to act as they think best, that they be. lieve the decision is a good one is never a reason for it; they must have reasons for their beliefs. 
lead us. Occasional deviations from the canons of good reasoning can be dismissed as mistakes, but when constant use is made of a pattern of argumentation completely devoid of logical validity it is time to distinguish between myth and rhetoric on the one hand and reality on the other. And the law should be understood to encompass reality, not rhetoric.

\section{The Possibility of a Criterion of Identily}

If the thesis of the limits of law is right, there must be a criterion of identity which sets necessary and sufficient conditions, satisfaction of which is a mark that a standard is part of a legal system. Austin's criterion of identity was that all and only the general commands of one sovereign are part of one legal system. Hart has criticized this criterion and suggested another. According to his theory every legal system contains a rule of recognition directed at the courts and imposing on them an obligation to apply those standards which fulfill various criteria set out in the rule. ${ }^{49}$ The rule of recognition is a cus. tomary rule arising out of the behavior of law-enforcing officials through a period of time. The rest of the laws of the system are valid because they fulfill the conditions set out in the rule of recognition. The general criterion of identity of all legal systems is that each contains a rule of recognition and all those laws satisfying the conditions it stipulates.

Professor Dworkin claims that no adequate criterion of identity can be formulated and that therefore the thesis of the limits of law must be rejected. He directs his attack against Hart's criterion and employs two arguments to show that neither Hart's nor any other criterion of identity can account for the existence of legal principles. I shall argue that one of Professor Dworkin's arguments contains a valid criticism of Hart but does not bear on the possibility of formulating a somewhat different criterion of identity, whereas his second argument fails altogether.

"Hart's sharp distinction between acceptance and validity," the first argument runs, "does not hold. If we are arguing for the principle that a man should not profit from his own wrong, we could cite the acts of courts and legislatures that exemplify it, but this speaks as much to the principle's acceptance as its validity. (It seems odd to

49. For arguments supporting this interpretation of Hart's doctrine, see Raz, supra note 38 , at $807-08$ \& $\mathrm{nn} .23-24$. 
speak of a principle as being valid at all, perhaps because validity is an all-or-nothing concept, appropriate for rules, but inconsistent with a principle's dimension of weight.)" ${ }^{\circ 0}$ The concept of validity is snid to be inconsistent with the principle's dimension of weight on the ground that one establishes a principle's validity by showing that it has "institutional support"; but the amount of support a principle enjoys determines its weight and is a matter of degree: "[T]he more support we found, the more weight we could claim for the principle."s1 But this is surely mistaken. A principle might have been referred to frequently by the courts as binding, but have little weight. The degree of support may sometimes be evidence for a principle's weight, but it need not be and the two notions are not logically related.

Legal principles may be valid in precisely the same way that rules are. They may, for example, be enacted in the constitution or in a statute, as some of Professor Dworkin's own examples show. It is true, though, that some legal principles are law because they are accepted by the judiciary. But this is true of rules as well as principles. It is, however, an important point which does necessitate a modification of Hart's criterion of identity. But here again Professor Dworkin claims too much. He claims that if the master rule says merely that whatever other rules the community accepts are legally binding then it fails to act as an identifying criterion distinguishing between law and social norms. ${ }^{52}$ Had all social customs in all countries been legally binding this would have been a valid criticism. Some countries, however, do not recognize custom as a source of law at all. Those legal systems which do regard customs as legally binding do so only if they pass certain tests. These tests, if they are not set out in a statute or some other law, are laid down by the rule of recognition, which determines under what conditions social customs are binding in law.

The rule of recognition, therefore, does serve to explain the legal status of general community customs. It cannot, however, explain in the same way the legal status of judicial customs. Since it is itself a judicial custom it cannot confer any special status on other judicial customs. Judicial rule-making, as I indicated above, differs in this respect from the evolution of principles by the courts. A rule becomes binding by being laid down in one case as a precedent. It does not

50. Dworkin, supra note 2, at 42 [55].

51. Id. at 41 [55].

52. Id. at $43-44[5 \hbar-58]$. 
have to wait until it is accepted in a series of cases to be binding. It is binding because of the doctrine of precedent which is part of our rule of recognition. Principles evolved by the courts become binding by becoming a judicial custom. They are part of the law because they are accepted by the courts, not because they are valid according to the rule of recognition.

Hart's criterion of identity must be modified. A legal system consists not only of one customary rule of the law enforcing agencies and all the laws recognized by it, but of all the customary rules and principles of the law enforcing agencies and all the laws recognized by them. ${ }^{53}$ This is an important modification, but it preserves the fundamental point underlying Hart's criterion and shared by many: namely, that law is an institutionalized normative system and that the fact that the enforcement of its standards is a duty of special law-enforcing agencies is one important feature which distinguishes it from many other normative systems. The importance of this feature of law is made manifest by distinguishing between legal and non-legal standards according to whether or not the courts have an obligation to apply them, either because they are themselves judicial custom or because judicial customs make their application obligatory.

Professor Dworkin has a second argument disputing the possibility of formulating an adequate criterion of identity. "True," he says, "if we were challenged to back up our claim that some principle is a principle of law, we would mention any prior cases in which that principle was cited, or figured in the argument .... Unless we could find some such institutional support, we would probably fail to make out our case ... . Yet we could not devise any formula for testing how much and what kind of institutional support is necessary to make a principle a legal principle." 54 In this passage Professor Dworkin is rejecting not merely Hart's version of the thesis of the limits of law but all versions of this thesis. He agrees that if legal and non-legal standards can be distinguished this could only be done by relying on the fact that only legal standards have adequate institutional support in the practice of the courts. He denies, however, the possibility of a general explanation of what counts as adequate institutional support. It follows that it is impossible to provide a general account of the difference between legal and non-legal standards and the thesis of the

53. For a more precise formulation of the critcrion and a more detailed examination of the problem, see Raz, supra note 38.

54. Dworkin, supra note 2, at 41 [55]. 
limits of law must be abandoned. What is the force of this argument? If a legal system consists, as I have suggested, of those standards which the courts are bound to recognize, we must agree with Professor Dworkin that we need a general explanation of what counts as adequate institutional support. For laws are binding on the courts either because judicial customs make their recognition obligatory or because they are themselves judicial customs. Thus the acceptability of the thesis of the limits of law depends on our ability to explain the concept of a judicial custom. But judicial customs are but a special case of social customs.

What we need is an adequate explanation of the concept of a customary norm. Once we have it we will know what judicial custom is and will have a complete criterion of identity. Hart has provided such an explanation. No doubt it is possible to improve on it, but there is no reason to suppose that the concept of a customary norm defies analysis. It is true that an analysis of the concept does not give us a decision procedure determining for every principle or rule whether or not it has sufficient support to be regarded as a judicial custom. Borderline cases will remain; they must remain, for customary norms evolve gradually. But Dworkin's is a very weak argument, which rejects a distinction because it admits the existence of borderline cases.

55. It is worth reminding ourseives that not every principle is evolved by the courts; many result from legislative action. 